\title{
Recovery of Phenolic Compounds from Red Grape Pomace Extract through Nanofiltration Membranes
}

\author{
Jaime A. Arboleda Mejia ${ }^{1}$, Arianna Ricci ${ }^{1,2}$, Ana S. Figueiredo $\left.{ }^{3,4}{ }^{(}\right)$, Andrea Versari $\left.{ }^{1,2}{ }^{(}\right)$, \\ Alfredo Cassano ${ }^{5}$ (D), Giuseppina P. Parpinello ${ }^{1,2, *(\mathbb{D})}$ and Maria N. De Pinho 4 (D) \\ 1 Department of Agricultural and Food Sciences, University of Bologna, Piazza Goidanich 60, \\ 47521 Cesena (FC), Italy; jaime.arboleda@studio.unibo.it (J.A.A.M.); arianna.ricci4@unibo.it (A.R.); \\ andrea.versari@unibo.it (A.V.) \\ 2 Interdepartmental Centre for Industrial Agrofood Research, University of Bologna, Via Quinto Bucci 336, \\ 47521 Cesena (FC), Italy \\ 3 CeFEMA/Departmental Area of Chemical Engineering, Instituto Superior de Engenharia de Lisboa, Instituto \\ Politécnico de Lisboa, Rua Conselheiro Emídio Navarro 1, 1959-007 Lisbon, Portugal; asofia@deq.isel.ipl.pt \\ 4 CeFEMA/Department of Chemical Engineering, Instituto Superior Técnico, Universidade de Lisboa, \\ Av. Rovisco Pais 1, 1049-001 Lisbon, Portugal; marianpinho@tecnico.ulisboa.pt \\ 5 Institute on Membrane Technology, ITM-CNR, c/o University of Calabria, via P. Bucci, 17/C, \\ I-87036 Rende (Cosenza), Italy; a.cassano@itm.cnr.it \\ * Correspondence: giusi.parpinello@unibo.it
}

Received: 24 September 2020; Accepted: 9 November 2020; Published: 12 November 2020

\begin{abstract}
The winemaking process generates a large amount of residues such as vine shots, stalks, grape pomace, and wine lees, which were only recently considered for exploitation of their valuable compounds. The purpose of this work was to investigate the performance of nanofiltration for the recovery of phenolic compounds, with bioactive capacity like antioxidant, from red grape pomace extract. Four membranes were compared in this study-three cellulose acetate (CA series: lab-prepared by phase inversion) and one commercial (NF90). All membranes were characterized for their hydraulic permeability and rejection coefficients to reference solutes like saccharose, glucose, raffinose, polyethylene glycol, sodium chloride, and sodium sulfate. Permeation flowrates and rejection coefficients towards total phenolics content, antioxidant activity, proanthocyanidins, glucose and fructose were measured in the nanofiltration of grape pomace extract using selected operating conditions. Among the investigated membranes, the CA400-22 exhibited the highest permeate flux $\left(50.58 \mathrm{~L} / \mathrm{m}^{2} \mathrm{~h}\right.$ at 20 bar and $25^{\circ} \mathrm{C}$ ), low fouling index (of about $23 \%$ ), the lowest rejection coefficients towards the reference solutes and the best performance in terms of separation between sugars and phenolic compounds. Indeed, the observed rejections for glucose and fructose were $19 \%$ and $12 \%$, respectively. On the other hand, total phenolics content and proanthocyanidins were rejected for $73 \%$ and $92 \%$, respectively.
\end{abstract}

Keywords: antioxidants; biorefinery; process optimization; fractionation; sustainability; winemaking exploitation

\section{Introduction}

The wine industry, with estimated worldwide annual grape processing of 78 million tons, produces one of the most abundant agro-waste resources represented by leaves, stems, pomaces (including grape skins and seeds) and lees [1].

The oenological wastes are usually conferred to distilleries for ethanol and tartaric acid recovery, or alternatively used as animal feed, fertilizers, or vineyard amendment [2,3]. However, organic waste disposal practices might have environmental impacts, causing soil and groundwater contamination, 
unpleasant odors, plant pathogen vectors (pests and flies) attraction, and the depletion of oxygen in the soil and groundwater, caused by tannins and other compounds degradation [4,5]. In recent times, the valorization of agro-wastes was boosted through the biorefinery approach, offering a great potential for wine companies to reduce the environmental impact and create profit, adopting sustainable practices that deal with the principles of the Circular Economy [6].

Among wastes, grape pomaces constitute a valuable source of polyphenolic compounds (flavonoids, tannins, and benzoic acids derivatives), which are biomolecules of both technological and nutraceutical interest, acting as antioxidants in biological matrices, through the inhibition of lipid peroxide radicals and reactive oxygen species [7-9]. In addition, the pomaces contain molecules of biological interest, such as essential oils, proteins, minerals, sugars, dietary fibers, and pectins, which might enhance the nutritional value of food ingredients and bioactive supplements obtained by oenological waste valorization $[4,10,11]$. Several studies demonstrated the protection activity of grape seed and pomace extracts against microbial inflammation, cancer, and degenerative diseases [12-15]. A virtuous oenological chain might consider the valorization of massive pomace wastes by adopting highly sustainable processes for the recovery of polyphenols. In this view, several research studies were carried out for substituting conventional solvent extraction procedures and avoiding impact swapping [16,17]. Among them, ultrasound and microwaves-assisted extractions in combination with aqueous solvent as well as non-conventional (solvents free) methods showed their potential in guaranteeing safe and high-quality of polyphenolic extracts [18-21]. Caldas et al. [22] found that ultrasound-assisted extraction showed the best phenolic recovery from grape skin of sparkling production, in comparison to conventional methods and microwave-assisted extraction. High amounts of anthocyanins and tannins were recovered from fermented grape pomace through a subcritical water extraction method [23]. The use of $\beta$-cyclodextrin was also proposed as a green extraction technique for isolating bioactive phenolics from grape pomace [24]. Recently, Meini et al. [25] reported the use of grape pomace as carbon source and inducer in submerged fermentation cultures of Aspergillus niger, proposing new routes for grape pomace valorization.

In this context, membrane processes represent a new frontier in bioactive compound exploitation being a powerful alternative to conventional methodologies, due to their low energy and no-additives requirements, mild temperature and pressure conditions, high separation efficiency and easy scale up [17]. In particular, pressure-driven membrane operations such as microfiltration (MF), ultrafiltration (UF), nanofiltration (NF), and reverse osmosis (RO) were largely investigated in the last few years, for the separation, purification, and concentration of natural antioxidants from several agro-food by-products, including olive mill wastewaters [26], artichoke brines [27], bergamot juice [28], and wine lees [29]. The use of UF membranes with molecular weight cut-off (MWCO) in the range 2-100 kDa was recently investigated for the fractionation of phenolic compounds from subcritical water grape pomace extract and the separation of these compounds from other co-extracted components [30]. On the other hand, the application of NF for the recovery of these compounds from grape pomace is still a matter of research.

In this work, we evaluated the feasibility of phenolic compounds recovery from red grape pomace through a combination of ultrasound-assisted enzymatic extraction, followed by a membrane separation process. The extraction parameters for grape pomace, were optimized by considering different enzymatic dosages and the number of ultrasound cycles. Afterwards, the extract was fractionated by means of three flat-sheet cellulose acetate membranes prepared in the laboratory. Membranes were characterized for their hydraulic permeability and rejection towards reference solutes. Their performances in terms of productivity, fouling index, cleaning efficiency, and selectivity towards target compounds was evaluated and compared with that of a commercial NF membrane. The grape pomace extract and the membrane fractions were characterized in terms of total phenolics content, proanthocyanidins, turbidity, antioxidant activity, glucose, and fructose. Results were discussed in terms of composition of the extracts and membrane performances to improve their application for bioactive compound extraction from food waste. 


\section{Materials and Methods}

\subsection{Red Grape Pomace}

The red grape pomace (a mixture of $60 \%$ cabernet sauvignon, 30\% Sangiovese, and 10\% Syrah) was collected from a local winery (Terre Naldi, Faenza, Italy), stored at $-20{ }^{\circ} \mathrm{C}$ and dried at $50{ }^{\circ} \mathrm{C}$ for $24 \mathrm{~h}$, before use.

\subsection{Ultrasonic-Assisted Enzymatic Extraction}

The extraction of polyphenols from grape pomace was carried out by means of an enzymatic hydrolysis with pectolytic enzymes (Lafase ${ }^{\circledR}$ He Grand Cru from Laffort, Bordeaux, France) coupled with ultrasonic irradiation, according to the methodology reported by [31], with some modifications related to the sonication power and number of operation cycles. In particular, Ultrasonic irradiation was applied by means of a High Intensity Ultrasonic Liquid Processor (VCX 50s-VC 75, Sonics, Newtown, CT, USA), at $16 \mathrm{~W}$, for a different number of cycles (from 4 to 10), for $1 \mathrm{~min}$.

To optimize the conditions a three-level Design of Experiment (DoE was used in this study. In brief, $0.250 \mathrm{~g}$ of dried grape pomace were mixed with $20 \mathrm{~mL}$ of succinic acid (50 mM) - borax (50 mM) buffer $(\mathrm{pH} 4.0)$ at $40{ }^{\circ} \mathrm{C}$ for $2 \mathrm{~h}$ exposure time $\left(\mathrm{t}_{(\mathrm{h})}\right)$ and three enzymatic dosages $\left(10,20\right.$ or $30 \mathrm{mg} \mathrm{g}^{-1}$ of dried pomace). The DoE consisted of thirteen trial replicates. Optimal conditions were settled according to the results of DoE and used to obtain a $5 \mathrm{~L}$ extract to feed the nanofiltration system.

Before the NF treatment, the solution was prefiltered by using a nylon filter with a hole diameter of $3 \mathrm{~mm}$, in order to achieve a solid-liquid separation.

\subsection{Nanofiltration Membranes}

Three cellulose acetate (CA) laboratory-made membranes coded as CA400-22, CA316-70, and CA316 were prepared at the Department of Chemical Engineering of the Instituto Superior Tecnico (Portugal), according to the phase inversion method [32]. Among them, the membrane CA316-70 was further subjected to annealing treatment. Membrane-casting solutions and film-casting conditions are reported in Table 1. Cellulose acetate, acetone, formamide, and magnesium perchlorate were of analytical grade (Merck Millipore, Darmstadt, Germany). In parallel, permeation experiments with a commercially available thin-film composite NF membrane (NF90, Dupont Filmtec, Wilmington, DE, USA) were carried out. Its characteristics are reported in Table 2.

Table 1. Film casting conditions and casting solutions used for the production of nanofiltration (NF) membranes.

\begin{tabular}{|c|c|c|c|}
\hline & \multicolumn{3}{|c|}{ Membrane Type } \\
\hline & CA316 & CA316-70 & CA400-22 \\
\hline \multicolumn{4}{|l|}{ Casting solution (wt.\%) } \\
\hline Cellulose acetate 398 & 17 & 17 & 17 \\
\hline Acetone & 69.2 & 69.2 & 61 \\
\hline Formamide & & & 22 \\
\hline Magnesium perchlorate & 1.45 & 1.45 & \\
\hline Water & 12.35 & 12.35 & \\
\hline \multicolumn{4}{|l|}{ Casting conditions } \\
\hline $\begin{array}{l}\text { Temperature of coagulation bath } \\
\text { solution }\left({ }^{\circ} \mathrm{C}\right)\end{array}$ & 0 & 0 & 0 \\
\hline Temperature of atmosphere $\left({ }^{\circ} \mathrm{C}\right)$ & $20-25$ & $20-25$ & $20-25$ \\
\hline Solvent evaporation time (min) & 1 & 0.5 & 0.5 \\
\hline Gelation medium & ice cold water $(1-2 \mathrm{~h})$ & ice cold water(1-2 h) & ice cold water $(1-2 \mathrm{~h})$ \\
\hline \multicolumn{4}{|l|}{ Annealing conditions } \\
\hline Annealing medium & & hot water & \\
\hline Annealing time (min) & & 11 & \\
\hline Annealing temperature $\left({ }^{\circ} \mathrm{C}\right)$ & & 70 & \\
\hline
\end{tabular}


Table 2. Characteristics of the NF90 membrane.

\begin{tabular}{lc}
\hline \multicolumn{1}{c}{ Membrane Material } & Aromatic Polyamide \\
\hline MWCO (Da) & $200^{\mathrm{c}}$ \\
Stabilized salt rejection $(\%)$ & $>97.0^{\mathrm{a}}$ \\
Max. inlet pressure (bar) & 41 \\
Max. operating temperature $\left({ }^{\circ} \mathrm{C}\right)$ & 45 \\
pH operating range & $2-11^{\mathrm{c}}$ \\
Contact angle $\left({ }^{\circ}\right)$ & $28.6^{\mathrm{b}}$ \\
Zeta potential at $\mathrm{pH} 7(\mathrm{mV})$ & $-9.1^{\mathrm{b}}$ \\
\hline 2000 ppm $\mathrm{MgSO}_{4}, 25^{\circ} \mathrm{C}$ and $15 \%$ recovery at 4.8 bar; ${ }^{\mathrm{b}}$ Data from Kong et al. [33]; \\
\end{tabular}

All membranes were characterized for water permeability and rejection coefficients to reference solutes including D-(+)-glucose, raffinose, polyethylene glycol (PEG $1000 \mathrm{Da})$, sodium chloride, sodium sulfate, and ethanol. Tests were carried out according to a total recycle configuration (recycling both permeate and retentate in the feed reservoir) in selected conditions of temperature $\left(25 \pm 1{ }^{\circ} \mathrm{C}\right)$ and feed flowrate $(0.8 \mathrm{~L} / \mathrm{min})$, by using feed solutions with a solute concentration of $600 \mathrm{ppm}$. The water permeability of the membranes was obtained by the linear regression of the water flux against the transmembrane pressure (TMP). The average crossflow velocity was $0.17 \mathrm{~m} / \mathrm{s}$ and the corresponding Reynolds number was 4000. A force balance (pressure forces $=$ shear forces) in the feed chamber of the permeation cells allowed the estimation of non-significant shear forces, due to the negligible pressure drop in the feed circulation stream.

\subsection{Experimental Set-Up and Procedures}

The permeation experiments were carried out in the laboratory filtration unit illustrated in Figure 1. The core of the set-up included a flat plate stainless steel cross-flow cell, with two detachable parts separated by a porous plate supporting the membrane with an active filtration area of $13.2 \times 10^{-4} \mathrm{~m}^{2}$. An important feature of the membrane cell is the conical shape of the upper part-pressurized feed side - to induce a feed turbulent flow and minimize solute accumulation at the membrane surface (Figure 2).

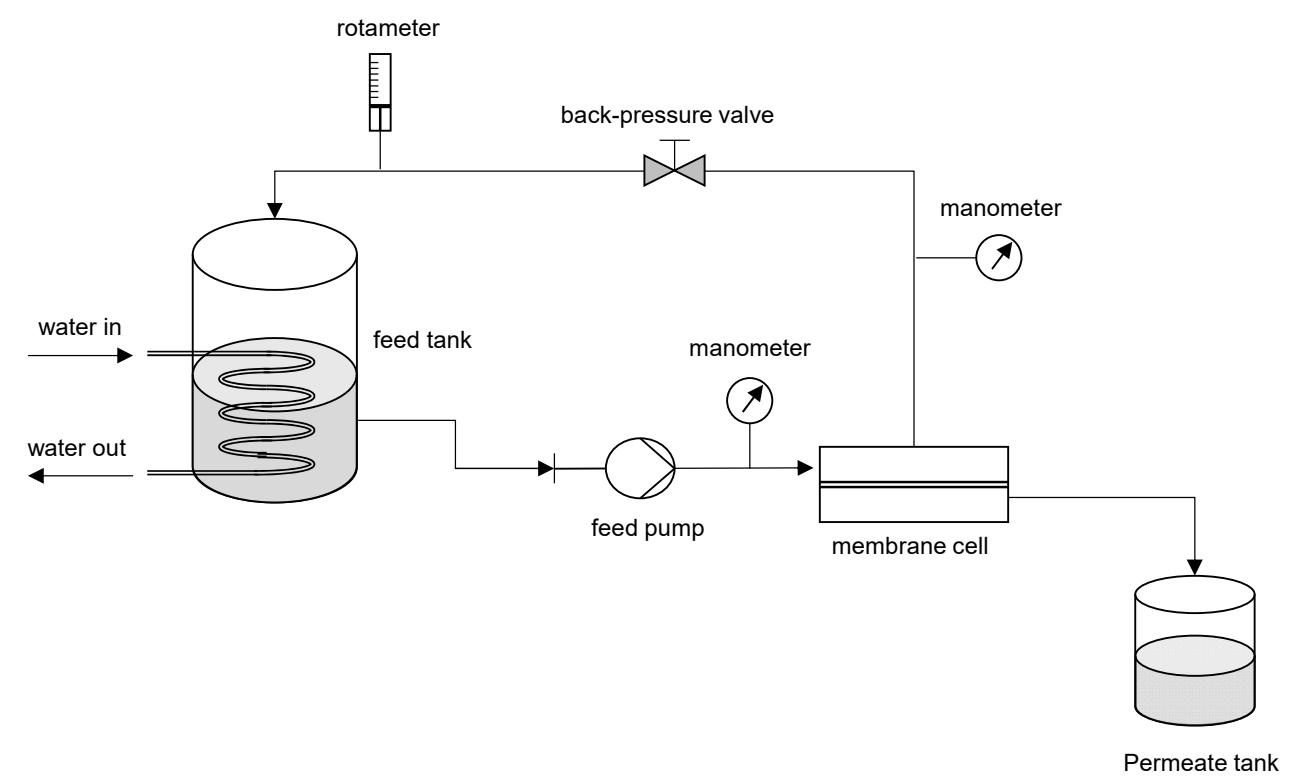

Figure 1. Schematic of lab-scale filtration unit including-water out; water in; feed tank; rotameter; back-pressure valve; manometer; membrane cell; feed pump; and permeate tank. 


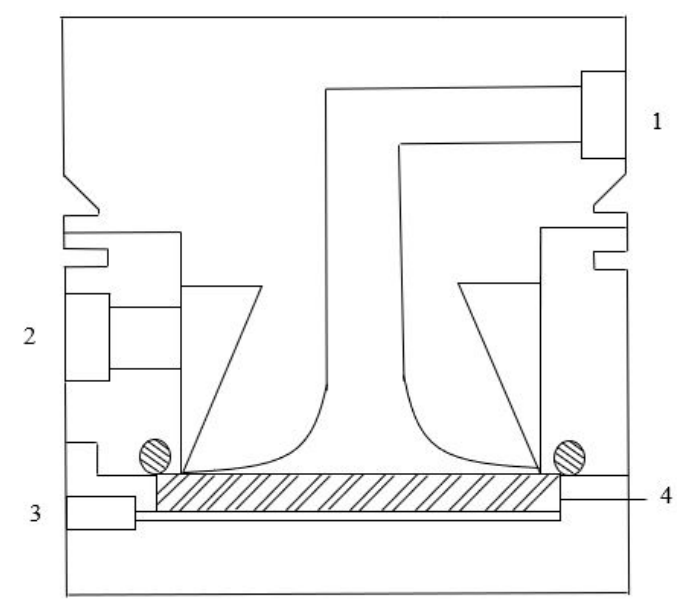

Figure 2. Cross-section of the membrane cell. 1. Feed inlet; 2. Feed outlet; 3. Permeate stream; 4 . Porous stainless-steel plate (membrane support). Figure adapted from [34].

Before the permeation tests, the membranes were compacted by circulation of deionized water at constant operating pressure of 35 bar for $2 \mathrm{~h}$, in order to minimize any effect on the membrane structure during the tests, due to the pressure to which they are subjected, and to obtain a steady flux. Experiments were carried out in recirculation mode with the retentate being recirculated into the feed tank, in selected conditions of temperature $\left(25 \pm 1^{\circ} \mathrm{C}\right)$ and pressure $(20 \mathrm{bar})$. Approximately $5 \mathrm{~L}$ of pomace extract were used as feed.

The permeate flux $\left(J_{p}\right)$, expressed as $\mathrm{L} / \mathrm{m}^{2} \mathrm{~h}$, was calculated as follows:

$$
J_{p}=\frac{V_{p}}{A \times t}
$$

where $V_{p}$ is the volume of permeate collected during the time interval $t$ and $A$ is the membrane surface area of permeation.

To investigate the causes of the permeate flux reduction compared to the one of water permeation, the water permeate flux before and after the experiments with grape pomace was measured. The fouling index $(F I)$ was estimated by comparing the pure water permeability before and after the NF experiments, according to the following equation:

$$
F I(\%)=\left(1-\frac{W_{p 1}}{W_{p 0}}\right) \times 100
$$

where $W_{p 0}$ and $W_{p 1}$ are the pure water permeability, before and after each nanofiltration run, respectively.

To measure the water permeability after the NF process, the grape pomace extract was removed from the plant. Then, the plant was filled with deionized water and the water permeability at a temperature of $25 \pm 1{ }^{\circ} \mathrm{C}$ at a feed flow rate of $0.8 \mathrm{~L} / \mathrm{min}$ was measured. Afterwards, the membranes were washed four times by flushing with deionized water at a temperature of $25 \pm 1{ }^{\circ} \mathrm{C}$; hence, deionized water was recirculated for $30 \mathrm{~min}$ without any pressure in the system at a temperature of $25 \pm 1{ }^{\circ} \mathrm{C}$ and at a feed flowrate of $0.8 \mathrm{~L} / \mathrm{min}$, separately collecting the permeate stream. At the end of the process, the deionized feed water and the permeate collected during this time were discarded. The process was repeated with a new amount of deionized water for $30 \mathrm{~min}$ in the same conditions and the permeability with deionized water was re-measured. The cleaning efficiency $(C E)$ was evaluated by using the water flux recovery, according to the following equation:

$$
C E(\%)=\left(\frac{W_{p 2}}{W_{p 0}}\right) \times 100
$$


where $W_{p 2}$ is the water permeability measured after the cleaning process.

\subsection{Analytical Evaluations}

Feed $(\mathrm{F})$, permeate $(\mathrm{P})$ and retentate $(\mathrm{R})$ samples from NF experiments were immediately refrigerated and kept at $4{ }^{\circ} \mathrm{C}$ until analyzed for total phenolics, proanthocyanidins content, antioxidant capacity, sugars (glucose and fructose), $\mathrm{pH}$, and turbidity.

The total phenolics content (TPC) was determined through the Folin-Ciocalteau method, based on the redox reaction of phenolic compounds with a mixture of phosphotungstic $\left(\mathrm{H}_{3} \mathrm{PWO}_{12} \mathrm{O}_{40}\right)$ and phosphomolybdic $\left(\mathrm{H}_{3} \mathrm{PMO}_{12} \mathrm{O}_{40}\right)$ acids in an alkaline medium to create a blue complex [35]. The reaction was performed by mixing a $0.250 \mathrm{~mL}$ sample aliquot, $0.5 \mathrm{~mL}$ of Folin-Coicalteu reagent (diluted 1:4) and $1.75 \mathrm{~mL}$ of a $15 \%$ sodium carbonate solution. After $1 \mathrm{~h}$, the absorbance was read by using an UV-vis spectrophotometer (UV-1700 Shimadzu), at a wavelength of $725 \mathrm{~nm}$. The results were expressed as mg of Gallic Acid Equivalent (GAE)/100 g dry matter.

The quantification of proanthocyanidins was carried out by means of a spectrophotometric assay with the 4-dimethyl-amino cinnamaldehyde reagent (DMAC), according to the method previously reported [36]. Results were expressed as $\mathrm{mg}$ of (+)-Catechin Equivalents (CE)/100 g dry weight. The monosaccharides (D-glucose and $\mathrm{D}$-fructose, expressed as $\mathrm{mg} / 100 \mathrm{~g}$ dry matter) were determined by an enzymatic assay (Megazyme, Chicago, IL, USA). The analysis was based on the sequential reactions that begin after the addition of hexokinases (HK) and phosphoglucose isomerase (PGI), for the determination of glucose and fructose, respectively. The amount of NADPH formed throughout the reactions, which was measured spectrophotometrically at an absorbance of $340 \mathrm{~nm}$, was stoichiometric with the amount of d-glucose and d-fructose present in the sample. The $\mathrm{pH}$ value was measured by potentiometry (HANNA 209 pH meter, Merk, Darmstadt, Germany), whereas turbidity (expressed as NTU) was measured by means of a compact infrared turbidity meter (AL250T-IR, Aqualytic ${ }^{\circledR}$, Dortmund, Germany).

The rejection of NF $(R)$ membranes towards specific compounds was calculated according to the following equation:

$$
R(\%)=\left(1-\frac{C_{p}}{C_{f}}\right) \times 100
$$

where $C_{p}$ and $C_{f}$ are the concentration of specific compounds in the permeate and feed samples stream, respectively.

The antioxidant capacity was measured by means of the 2,2'-azinobis-(3-ethylbenzothiazoline-6sulfonic acid (ABTS) assay according to Re et al. [37] at $734 \mathrm{~nm}$, and calculated as percentage of radical scavenged:

$$
A C(\%)=\left(\frac{R_{0-} R_{1}}{R_{0}}\right) \times 100
$$

where $R_{0}$ is the absorbance value of the blank and $R_{1}$ is the absorbance of the sample. Results were reported as percentage of the radical scavenging of the sample. This method was based on the ability of antioxidants to interact with the ABTS radical, decreasing its absorbance to $734 \mathrm{~nm}$. In brief, a radical solution was prepared, which was based on $7 \mathrm{mM}$ ABTS (2,2'-azino-bis-(-3-ethylbenzothiazoline-6-sulfonic acid)) and $2.45 \mathrm{mM}$ sodium persulfate, then, the solution was left in the dark, at room temperature, for $16 \mathrm{~h}$ before use. Subsequently, the ABTS stock solution was added in acetate buffer to an absorbance range of 0.68 to 0.70 , at a wavelength of $734 \mathrm{~nm}$. For analysis, $2.9 \mathrm{~mL}$ of the ABTS reagent solution was mixed with $0.1 \mathrm{~mL}$ microliters of the sample and the blank was prepared by adding $2.9 \mathrm{~mL}$ ABTS reagent solution to $0.1 \mathrm{~mL}$ distilled water. After $300 \mathrm{~min}$, the absorbance was read by using an UV-Vis spectrophotometer at $734 \mathrm{~nm}$. Moreover, the antioxidant capacity AC-DPPH was evaluated using 1,1-diphenyl-2-picryl-hydrazyl free radical (DPPH) [38] characterized by an intense purple red color, which bleaches when reduced in the presence of a molecule capable of neutralizing by transfer of proton or electron. Shortly, the DPPH reagent was 
dissolved in pure methanol, subsequently it was brought to an absorbance of $0.7( \pm 0.010)$. The solution was kept refrigerated at $4{ }^{\circ} \mathrm{C}$, before use. For analysis, $2.9 \mathrm{~mL}$ of the DPPH solution was mixed with $0.1 \mathrm{~mL}$ of the sample, and the blank was prepared by adding $2.9 \mathrm{~mL}$ DPPH solution to $0.1 \mathrm{~mL}$ distilled water. Subsequently, the solution was stirred and kept in the dark at room temperature. After $1 \mathrm{~h}$, it was read on a spectrophotometer at a wavelength of $517 \mathrm{~nm}$, against methanol. Both analyses were carried out by using an UV-Vis spectrophotometer (Cary 60, Agilent Technologies, Santa Clara, CA, USA). Results were expressed as percentage of radical scavenging activity.

\subsection{Statistical Analysis}

Data are presented as mean values \pm standard deviation (SD) obtained from three replicated analyses. Significant differences were evaluated by means of One-Way ANOVA analysis of variance $(p \leq 0.05)$ and Tukey's HSD post-hoc test, using statistical software Minitab ${ }^{\circledR} 17.10$ (Minitab, Ltd., Coventry, UK).

\section{Results and Discussion}

\subsection{Membrane Characterization}

The rejections for the NF membranes towards a set of reference solutes, salts, and ethanol, decreased as follows (Table 3):

NF90 > CA316-70 > CA316 > CA400-22

Table 3. Rejections of NF membranes to specific solutes, salts, and ethanol (Test conditions: feed solute concentration, $600 \mathrm{ppm}$; temperature, $25 \pm 1^{\circ} \mathrm{C}$; feed flowrate, $0.8 \mathrm{~L} / \mathrm{min}$; pressure, $20 \mathrm{bar}$ ).

\begin{tabular}{lccccccc}
\hline $\begin{array}{c}\text { Membrane } \\
\text { Type }\end{array}$ & $\begin{array}{c}\text { Saccharose } \\
\mathbf{( \% )}\end{array}$ & $\begin{array}{c}\text { Glucose } \\
\mathbf{( \% )}\end{array}$ & $\begin{array}{c}\text { Raffinose } \\
\mathbf{( \% )}\end{array}$ & $\begin{array}{c}\text { PEG } \\
\mathbf{( \% )}\end{array}$ & $\begin{array}{c}\mathbf{N a C l} \\
(\mathbf{\%})\end{array}$ & $\begin{array}{c}\mathbf{N a}_{\mathbf{2}} \mathbf{S O}_{\mathbf{4}} \\
\mathbf{( \% )}\end{array}$ & $\begin{array}{c}\text { Ethanol } \\
(\mathbf{\%})\end{array}$ \\
\hline NF90 & 100 & 100 & 100 & 99 & 95 & 99 & 50 \\
CA316-70 & 98 & 95 & 98 & 89 & 77 & 97 & 7 \\
CA316 & 70 & 50 & 77 & 55 & 27 & 86 & 1 \\
CA400-22 & 16 & 11 & 21 & 20 & 10 & 47 & 2 \\
\hline
\end{tabular}

PEG-polyethylene glycol.

The NF90 and the CA316-70 membranes presented rejections towards sodium sulfate of $99 \%$ and $97 \%$, respectively, and to sodium chloride of $95 \%$ and $77 \%$, respectively. On the other hand, the CA400-22 and CA316 membranes presented lower rejections to sodium sulfate ( $47 \%$ and $86 \%$, respectively) and to sodium chloride ( $10 \%$ and $27 \%$, respectively). However, there was still a differentiation between the two salts, as characteristic of NF membranes. The result reflected the characteristic behavior of NF membranes.

The water permeability data (see Figures S1-S4 in supplementary data) were in agreement with typical values of NF membranes, with the CA400-22 membrane exhibiting the highest value $\left(8.34 \mathrm{~L} / \mathrm{m}^{2} \mathrm{~h}\right.$ bar) and the NF90 membrane showing the lowest one $\left(3.75 \mathrm{~L} / \mathrm{m}^{2} \mathrm{~h}\right.$ bar).

\subsection{Grape Pomace Extract}

Phenolic compounds were extracted from grape pomace by means of an optimized ultrasonic-assisted enzymatic treatment as follows. Enzymatic dosage-10 $\mathrm{mg} \mathrm{g}^{-1}$; number of ultrasound cycles -4 with 1-min duration for each cycle. The physico-chemical composition of the grape pomace extract is reported in Table 4. 
Table 4. Physico-chemical characteristics of red grape pomace extract.

\begin{tabular}{lc}
\hline \multicolumn{1}{c}{ Parameter } & Value \\
\hline Turbidity (NTU) & $169 \pm 0.5$ \\
pH & $4.0 \pm 0.1$ \\
Total polyphenolics FC (mg GAE/100 g dw) & $260 \pm 10.3$ \\
AC DPPH (\% scavenging) & $16 \pm 0.3$ \\
AC ABTS (\% scavenging) & $41 \pm 3.5$ \\
Proanthocyanidins (mg CE/100g dw) & $49 \pm 6.2$ \\
Glucose (mg/100 g) & $46 \pm 0.0$ \\
Fructose (mg/100 g) & $403 \pm 0.1$ \\
\hline
\end{tabular}

FC: Folin-Ciocalteu; GAE: gallic acid equivalents; CE: (+)-catechin equivalents; dw: dry weight pomaces; and AC: antioxidant capacity.

The red grape pomace extract had a $\mathrm{pH}$ of 4.0 due to the use of the buffer solution, which contained succinic acid $\left(\mathrm{C}_{4} \mathrm{H}_{6} \mathrm{O}_{4}\right)$ and sodium borate $\left(\mathrm{Na}_{2} \mathrm{~B}_{4} \mathrm{O}_{7} \cdot 10 \mathrm{H}_{2} \mathrm{O}\right)$. The total phenolics content in the extract resulted on $260 \mathrm{mg} \mathrm{GAE} / 100 \mathrm{~g}$, using a solid-solvent ratio of 1:80 (w/v). Similar values were obtained by Nayak et al. [39], which reported a total phenolics content of $427.9 \mathrm{mg} \mathrm{GAE} / 100 \mathrm{~g}$ for the water extraction (solid-solvent ratio of 1:20 w/v) compared to the higher value of $801.6 \mathrm{mg}$ GAE/100 $\mathrm{g}$ obtained by the same author, with water-ethanol extraction (solid-solvent ratio of 1:20 w/v) of the Cabernet Sauvignon grape pomace. Differences in the extraction yield of polyphenolic compounds from grape pomaces might be discussed in the light of several technological factors, including grape variety and soil management, winemaking conditions of solvent type (aqueous, organic) and extraction technology [40].

The red grape pomace extract contained $46 \mathrm{mg} / 100 \mathrm{~g} \mathrm{dw}$ and $403 \mathrm{mg} / 100 \mathrm{~g}$ dw of glucose and fructose, respectively. The glucose content in the grape pomace was low $(0.046 \% \mathrm{dw})$, with an increase in the fructose extracted $(0.40 \% \mathrm{dw})$; both sugars were several orders of magnitude lower than previous reports after Pedras et al. [20], which obtained glucose and fructose contents of $2.8 \% \mathrm{dw}$ and $3.1 \% \mathrm{dw}$, respectively, in their red grape pomace extract.

The content of proanthocyanidins in the extract was $49.0 \mathrm{mg} \mathrm{CE} / 100 \mathrm{~g} \mathrm{dw}$ and higher values (in the range 100-250 mg catechin/100 g) were reported for different grape pomace varieties, including white grape varieties such as Sauvignon Blanc and Chardonnay, and red grape varieties such as Cabernet Sauvignon and Carménère [41]. It is worth noticing that values estimated by these authors include monomeric, oligomeric, and polymeric flavan-3-ols and that the total polyphenols obtained using stepwise methanol/water and acetone/water extractions were 10 order higher than those obtained by enzymatic-assisted extraction in this study [41].

The antioxidant capacity could be considered to be strong, intermediate, or weak when the radical DPPH scavenging activity was above $70 \%$, between 50 and $70 \%$, and below $50 \%$, respectively [42]. According to the cited ranking, the red grape pomace extract had a weak antioxidant activity, as measured by the DPPH radical scavenging assay $(16 \pm 0.3 \%)$, and showed increasing effectiveness when the ABTS was used as the reference radical $(41 \pm 3.5 \%)$. In both cases, the relatively low content of polyphenolic compounds in the extract, represented a limiting factor for their application as antioxidant; this limitation might be overcome by careful selection of the raw materials and optimization of the extraction parameters.

\subsection{Membrane Productivity}

Table 5 reports the average permeate fluxes $\left(J_{p}\right)$ of the grape pomace extract nanofiltration at 20 bar, with the four NF membranes. The CA400-22 membrane showed the highest permeate flux with a value of $50.58 \mathrm{~L} / \mathrm{m}^{2} \mathrm{~h}$, while the CA316 and the CA316-70 membranes showed quite similar permeate flux values ( 44.44 and $43.38 \mathrm{~L} / \mathrm{m}^{2} \mathrm{~h}$, respectively); on the other hand, the NF90 membrane showed the lowest permeate flux $\left(26.09 \mathrm{~L} / \mathrm{m}^{2} \mathrm{~h}\right)$. These results were in agreement with the rejection 
values measured for different solutes and data of water permeability. In particular, a strong correlation between the cut-off of the membranes and the permeate flux values could be inferred.

Table 5. Average permeate flux for selected membranes in the nanofiltration of red grape pomace extract (operating conditions: pressure, 20 bar; temperature, $25 \pm 1{ }^{\circ} \mathrm{C}$ ).

\begin{tabular}{lc}
\hline \multicolumn{1}{c}{ Membrane Type } & $J_{\boldsymbol{p}}\left(\mathbf{L} / \mathbf{m}^{2} \mathbf{h}\right)$ \\
\hline NF90 & $26.09 \pm 1.25^{\mathrm{C}}$ \\
CA316-70 & $43.38 \pm 0.9^{\mathrm{B}}$ \\
CA316 & $44.44 \pm 1.05^{\mathrm{B}}$ \\
CA400-22 & $50.58 \pm 2.55^{\mathrm{A}}$
\end{tabular}

Different superscript letter in properties are significantly different according to the Tukey's HSD test $(p \leq 0.05)$.

Commercial polymeric membranes such as DL2540 and GE2540 (from Osmonics, Minnetonka, MN, USA) with cut-off of 150-300 and $1000 \mathrm{Da}$, respectively, produced permeate fluxes of the order of $23-28 \mathrm{~L} / \mathrm{m}^{2} \mathrm{~h}$, when processing aqueous extracts from distilled fermented grape pomace at $8 \mathrm{bar}$, in the full recycle mode [43]. In this case, the effects observed in terms of flux declining were not in direct relation to the pore size, suggesting that the chemical nature of the membrane material plays a key role in the membrane performance.

\subsection{Fouling Index and Cleaning Efficiency}

Membrane fouling plays a leading role at different stages of the membrane filtration process and in the selection of a membrane for a specific application. Once membrane fouling occurs, it reduces the permeate flux, increases feed pressure, reduces productivity, increases membrane maintenance and operation costs due to membrane cleaning, and decreases the membrane lifetime [44]. The fouling index for the investigated membranes was calculated by measuring the water permeability before and after the filtration of the red grape pomace extract. According to the results in Table 6, the NF90 membrane showed the highest fouling index (40.53\%) followed by the CA316-70 membrane (35.97\%), the CA400-22 membrane (23.38\%), and lastly the CA316 membrane (13.39\%). The highest fouling index reported for the NF90 membrane could be explained due to the adsorption of organic compounds on the membrane surface through a possible formation of hydrogen bonds between the membrane polymer (polyamide) and organic compounds. Furthermore, according to the results reported by Arsuaga et al. [45], the adsorption of phenolic compounds on the membrane could be promoted by the hydrophobic interactions with the membrane material, playing an important role in the retention of solutes, a higher flux decline and a high fouling index. On the other hand, the permeate fluxes of UF and NF membranes might be severely decreased when treating low molecular weight hydrophobic solutes. In addition, the extent of the permeate fluxes reduction was affected by the hydrophilic/hydrophobic properties of the membrane material and the concentration of the solutes [46]. Accordingly, the three laboratory-made cellulose acetate membranes showed a low fouling index, when compared with the NF90 membrane.

A high recovery of the hydraulic permeability (89.41\%) was observed for the CA316 membrane after cleaning with distilled water. Similar results were noticed for the CA316-70 and the CA400-22 membranes, with recoveries of $80.10 \%$ and $80.57 \%$, respectively. According to the highest fouling index measured for the NF90 membrane, the cleaning efficiency for this membrane was the lowest, with a recovery of the initial water permeability being $60.26 \%$. Overall, an incomplete recovery of the hydraulic permeability in the membranes could be attributed to an irreversible fouling, which is a phenomenon associated with phenolic components being absorbed on the surface of the membranes [47]. 
Table 6. Hydraulic permeabilities in NF/cleaning cycles, fouling index, and cleaning efficiency of the selected membranes.

\begin{tabular}{lcccc}
\hline & \multicolumn{4}{c}{ Membrane Type } \\
\cline { 2 - 5 } & CA316 & CA316-70 & CA400-22 & NF90 \\
\hline$W_{p 0}\left(\mathrm{~L} / \mathrm{m}^{2} \mathrm{~h}\right.$ bar $)$ & 4.63 & 4.42 & 8.34 & 3.75 \\
$W_{p 1}\left(\mathrm{~L} / \mathrm{m}^{2} \mathrm{~h}\right.$ bar $)$ & 4.01 & 2.83 & 6.39 & 2.23 \\
$W_{p 2}\left(\mathrm{~L} / \mathrm{m}^{2} \mathrm{~h}\right.$ bar $)$ & 4.14 & 3.54 & 6.72 & 2.26 \\
Fouling index $(\%)$ & 13.39 & 35.97 & 23.38 & 40.53 \\
Cleaning efficiency $(\%)$ & 89.41 & 80.10 & 80.57 & 60.26 \\
\hline
\end{tabular}

$W_{p 0}$, water permeability before the NF of grape pomace extract; $W_{p 1}$, water permeability after the NF of grape pomace extract; and $W_{p 2}$, water permeability after cleaning with distilled water.

\subsection{Analyses of Membrane Selectivity}

The physico-chemical parameters of NF permeate samples in comparison to the red grape pomace extract are reported in Table 7. Minimal changes in $\mathrm{pH}$ values were noticed in all permeate fractions, when compared to the red grape pomace extract. Although the acids of the grape (malic and tartaric acid) were associated with a $\mathrm{pH}$ generally in the range of 3.2 and 4.0 [48], the $\mathrm{pH}$ of the present extract was due to the preparation of the buffer solution with succinic acid $\left(\mathrm{C}_{4} \mathrm{H}_{6} \mathrm{O}_{4}\right)$ and sodium borate $\left(\mathrm{Na}_{2} \mathrm{~B}_{4} \mathrm{O}_{7} \cdot 10 \mathrm{H}_{2} \mathrm{O}\right)$, establishing the $\mathrm{pH}$ value of 4.0.

Table 7. Physico-chemical characteristics of feed and permeate samples obtained in the NF of grape pomace extract.

\begin{tabular}{|c|c|c|c|c|c|}
\hline \multirow{2}{*}{ Parameter } & \multirow{2}{*}{ Feed } & \multicolumn{4}{|c|}{ Permeate } \\
\hline & & CA316 & CA316-70 & CA400-22 & NF90 \\
\hline Turbidity (NTU) & $169 \pm 0.5^{\mathrm{A}}$ & $2.9 \pm 0.4^{\mathrm{C}}$ & $2.2 \pm 0.5^{\mathrm{C}}$ & $7.2 \pm 0.9^{\mathrm{B}}$ & $1.5 \pm 0.4^{\mathrm{C}}$ \\
\hline $\mathrm{pH}$ & $4.0 \pm 0.1^{\mathrm{A}}$ & $3.7 \pm 0.1 \mathrm{AB}$ & $3.7 \pm 0.2^{\mathrm{B}}$ & $3.8 \pm 0.1 \mathrm{AB}$ & $3.6 \pm 0.0^{\mathrm{B}}$ \\
\hline Total polyphenol FC (mg GAE/100 g) & $260 \pm 10.3^{\mathrm{A}}$ & $54 \pm 4.1^{\text {В }}$ & $50 \pm 15.1^{\text {B }}$ & $70 \pm 2.7^{\mathrm{B}}$ & $9.1 \pm 6.3^{C}$ \\
\hline AC DPPH (\% scavenging) & $16 \pm 0.3^{\mathrm{A}}$ & $6.4 \pm 0.4^{C D}$ & $8.9 \pm 2 \mathrm{BC}$ & $11 \pm 0.9^{\mathrm{B}}$ & $5.6 \pm 0.3^{\mathrm{D}}$ \\
\hline AC ABTS (\% scavenging) & $41 \pm 3.5^{\mathrm{A}}$ & $3.5 \pm 0.1^{C}$ & $3.8 \pm 0.8^{\mathrm{C}}$ & $13.9 \pm 0.7^{\mathrm{B}}$ & n.d \\
\hline Proanthocyanidins (mg CE/100 g dw) & $49 \pm 0.7^{\mathrm{A}}$ & n.d & n.d & $4.0 \pm 1.7^{\mathrm{B}}$ & n.d \\
\hline Glucose $(\mathrm{mg} / 100 \mathrm{~g})$ & $46 \pm 0.0^{\mathrm{A}}$ & $5.7 \pm 0.0^{\mathrm{D}}$ & n.d & $37 \pm 0.0^{\mathrm{B}}$ & $12 \pm 0.0^{C}$ \\
\hline Fructose (mg/100 g) & $403 \pm 0.1^{\mathrm{A}}$ & $98 \pm 0.2^{C}$ & n.d & $354 \pm 0.4^{\mathrm{B}}$ & $27 \pm 0.0^{\mathrm{D}}$ \\
\hline
\end{tabular}

Different superscript letter in properties are significantly different according to the Tukey's HSD test $(p \leq 0.05)$. FC, Folin-Ciocalteu; GAE, gallic acid equivalents; $\mathrm{CE},(+)$-catechin equivalents; dw, dry weight pomaces; and AC, antioxidant capacity.

All membranes used allowed a significant reduction in turbidity of around $95 \%$. In particular, the NF90 membrane allowed a reduction in turbidity of $99.12 \%$. In parallel, the NF90 membrane showed the highest rejection coefficient towards the total polyphenols and antioxidant capacity. The rejection for total polyphenols was $97 \%$; for the antioxidant capacity the rejections were of $74 \%$ and $100 \%$ in relation to the analysis of DPPH and ABTS, respectively. Similar results were obtained by Cassano et al. [26] in the treatment of olive mill wastewaters with the same membrane obtaining a rejection for total polyphenols of $93 \%$. Rejection coefficients for polyphenols higher than $92 \%$ were also measured by Giacobbo et al. [49] in the treatment of winery wastewater generated in the second racking from red wine production, with a polypiperazine membrane having a MWCO of $300 \mathrm{Da}$ (NF270, from DOW-Filmtec, Edina, MN, USA).

Figure 3 displays the NF membranes' rejections to the different compounds of the grape pomace extracts. The CA400-22 membrane showed a rejection of about $73 \%$ to the total polyphenols and a rejection of about $60-70 \%$ to the antioxidant capacity. This membrane showed almost a total retention towards proantocyanidins (about 93\%) and allowed to recover most parts of the glucose and fructose in the permeate stream (rejection values of $19.5 \%$ and $12.5 \%$, respectively), obtaining a permeate rich in sugars. Therefore, this membrane offered the best performance in terms of separation between 
sugars and phenolic compounds. On the other hand, the CA316 and CA316-70 membranes presented a similar retention for the total phenolics (higher than 80\%) and antioxidant capacity (higher than $90 \%$ in the ABTS test), as well as high retention towards glucose and fructose, with values of $87 \%$ and $100 \%$, respectively, for the CA316 membrane, and a total retention of both compounds for the CA316-70 membrane. Similar retention values towards sugars and phenolic compounds were also measured by Galanakis et al. [50] in the treatment of winery sludge, with a composite fluoropolymer NF membrane of $1 \mathrm{kDa}$ (Etna 01PP from Alfa Laval, Nakskov, Denmark). This membrane successfully separated hydroxycinnamic acid derivatives from anthocyanins and flavonols in diluted and concentrated extracts, respectively. Recently, Yammine et al. [51] evaluated the rejection coefficients of several NF membranes, with MWCO in the range of 150-1000 Da, for several families of polyphenols from grape pomace. In agreement with our findings, membranes with MWCO between 500 and 1000 Da were able to recover polymeric proanthocyanidins in the retentate stream. On the other hand, membranes with MWCO between 300 and 600 Da was useful for the fractionation of monomeric phenolic families.

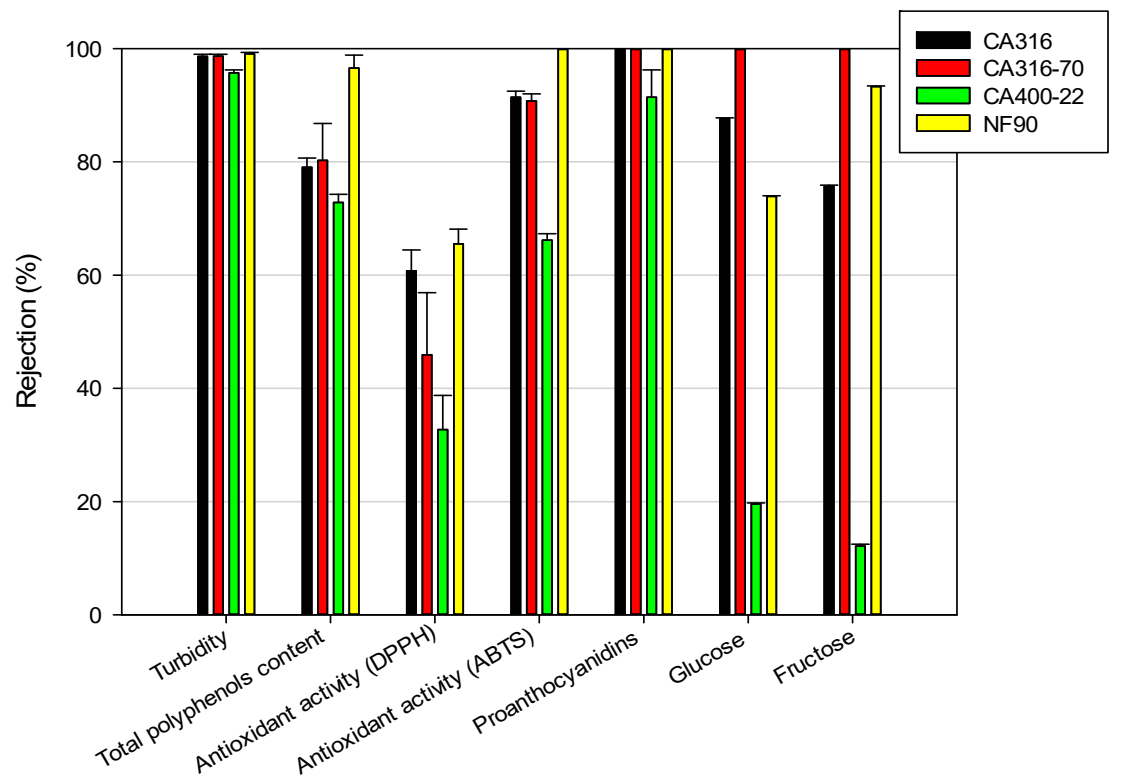

Figure 3. NF rejections to specific compounds and characteristics of grape pomace extract. Membrane: CA316, CA316-70, CA400-22, and NF90.

\section{Conclusions}

This work proposes a sustainable valorization of grape pomace through a combination of ultrasound-assisted enzymatic extraction and membrane processing. Cellulose acetate membranes in flat-sheet configuration were prepared, characterized, and evaluated for their selectivity towards phenolic compounds, proanthocyanidins, and sugars. Their performance was compared with that of a commercial nanofiltration membrane.

All tested membranes presented high retention coefficients towards phenolic compounds and proanthocyanidins and were suitable for concentration purposes. Among these membranes, the CA400-22 membrane exhibited low retention values for glucose and fructose (rejection values of $19.5 \%$ and $12.5 \%$, respectively) and rejections for phenolic compounds and proanthocyanidins of $73 \%$ and $92 \%$, respectively. Therefore, this membrane is a suitable candidate for phenolic compounds/sugars fractionation. In addition, its productivity was the highest in the selected operating conditions of extract processing through nanofiltration. The overall results indicate that the combination of an ultrasound-assisted enzymatic extraction with the development of tailor-made cellulose acetate membranes could be a useful and sustainable approach for the recovery of valuable fractions from red grape pomace of interest, for the production of innovative formulations with specific requirements for the pharmaceutical and food industry. 
Supplementary Materials: The following are available online at http://www.mdpi.com/2304-8158/9/11/1649/s1. Figure S1: Pure water permeability of the NF90 membrane. $W_{p 0}$, water permeability before the red grape pomace extract nanofiltration; $W_{p 1}$, water permeability after the red grape pomace extract; and $W_{p 2}$, water permeability after cleaning with water (operating conditions-feed flowrate of $0.8 \mathrm{~L} / \mathrm{min}$; Tof $25 \pm 1{ }^{\circ} \mathrm{C}$ ); Figure S2: Pure water permeability of the CA316 membrane. $W_{p 0}$, water permeability before the treatment of red grape pomace extract; $W_{p 1}$, water permeability after the treatment of red grape pomace extract; and $W_{p 2}$, water permeability after cleaning with water (operating conditions-feed flowrate, $0.8 \mathrm{~L} / \mathrm{min}$; T, $25 \pm 1{ }^{\circ} \mathrm{C}$ ); Figure S3: Pure water permeability of the CA316-70 membrane. $W_{p_{0}}$, water permeability before the treatment of red grape pomace extract; $W_{p 1}$, water permeability after the treatment of red grape pomace extract; and $W_{p 2}$, water permeability after cleaning with water (operating conditions-feed flowrate, $0.8 \mathrm{~L} / \mathrm{min}$; T, $25 \pm 1^{\circ} \mathrm{C}$ ); and Figure S4: Pure water permeability of the CA400-22 membrane. $W_{p 0}$, water permeability before the treatment of red grape pomace extract; $W_{p 1}$, water permeability after the treatment of red grape pomace extract; and $W_{p 2}$, water permeability after cleaning with water (operating conditions-feed flowrate, $0.8 \mathrm{~L} / \mathrm{min} ; \mathrm{T}, 25 \pm 1{ }^{\circ} \mathrm{C}$ ).

Author Contributions: Formal analysis, writing—original draft preparation, and data curation, J.A.A.M.; formal analysis, validation and resources, writing-review and editing, A.R.; methodology and software, A.S.F.; writing-review and editing, visualization, data curation, A.V.; Conceptualization, methodology and data curation, A.C.; conceptualization, investigation, resources, validation, supervision and writing-review and editing, G.P.P.; conceptualization, resources, methodology and supervision, M.N.D.P. All authors have read and agreed to the published version of the manuscript.

Funding: Authors M.N.D.P. and A.S.F. were financially supported by CeFEMA UID/CTM/04540/2013. Author J.A.A.M. was financially supported by a PhD and Marco Polo Fellowships from the University of Bologna, Italy.

Acknowledgments: Authors M.N.D.P. and A.S.F. are grateful to FCT-Fundação para a Ciência e Tecnologia, Portugal—for the financial support through CeFEMA UID/CTM/04540/2013. J.A.A.M. acknowledges the PhD program in "Agriculture, Environmental and Food Science and Technology" from the University of Bologna, Italy.

Conflicts of Interest: The authors declare no conflict of interest.

\section{References}

1. OIV. Statistics Unit of the International Organisation of Vine and Wine. OIV 2019 report on the world vitivinicultural situation. Int. Organ. Vine Wine 2019, 1, 1-23.

2. Drosou, C.; Kyriakopoulou, K.; Bimpilas, A.; Tsimogiannis, D.; Krokida, M. A comparative study on different extraction techniques to recover red grape pomace polyphenols from vinification byproducts. Ind. Crops Prod. 2015, 75, 141-149. [CrossRef]

3. Silva, M.L.; Macedo, A.C.; Malcata, F.X. Steam distilled spirits from fermented grape pomace. Food Sci. Technol. Int. 2000, 6, 285-300. [CrossRef]

4. Beres, C.; Costa, G.N.S.; Cabezudo, I.; da Silva-James, N.K.; Teles, A.S.C.; Cruz, A.P.G.; Mellinger-Silva, C.; Tonon, R.V.; Cabral, L.M.C.; Freitas, S.P. Towards integral utilization of grape pomace from winemaking process: A review. Waste Manag. 2017, 68, 581-594. [CrossRef] [PubMed]

5. Kammerer, D.; Claus, A.; Carle, R.; Schieber, A. Polyphenol screening of pomace from red and white grape varieties (Vitis vinifera L.) by HPLC-DAD-MS/MS. J. Agr. Food Chem. 2004, 52, 4360-4367. [CrossRef]

6. Devesa-Rey, R.; Vecino, X.; Varela-Alende, J.L.; Barral, M.T.; Cruz, J.M.; Moldes, A.B. Valorization of winery waste vs. the costs of not recycling. Waste Manag. 2011, 31, 2327-2335. [CrossRef]

7. Alonso, Á.M.; Guillén, D.A.; Barroso, C.G.; Puertas, B.; García, A. Determination of antioxidant activity of wine byproducts and its correlation with polyphenolic content. J. Agr. Food Chem. 2002, 50, 5832-5836. [CrossRef]

8. Xu, Y.; Simon, J.E.; Welch, C.; Wightman, J.D.; Ferruzzi, M.G.; Ho, L.; Passinetti, G.M.; Wu, Q. Survey of polyphenol constituents in grapes and grape-derived products. J. Agr. Food Chem. 2011, 59, 10586-10593. [CrossRef]

9. Rice-Evans, C.A.; Miller, N.J.; Paganga, G. Antioxidant properties of phenolic compounds. Trends Plant Sci. 1997, 2, 152-159. [CrossRef]

10. De Campos, L.M.A.S.; Leimann, F.V.; Pedrosa, R.C.; Ferreira, S.R.S. Free radical scavenging of grape pomace extracts from Cabernet sauvignon (Vitis vinifera). Bioresour. Technol. 2008, 99, 8413-8420. [CrossRef]

11. Llobera, A.; Canellas, J. Dietary fibre content and antioxidant activity of Manto Negro red grape (Vitis vinifera): Pomace and stem. Food Chem. 2007, 101, 659-666. [CrossRef] 
12. Mohansrinivasan, V.; Devi, C.S.; Deori, M.; Biswas, A.; Naine, S.J. Exploring the anticancer activity of grape seed extract on skin cancer cell exploring the anticancer activity of grape seed extract on skin cancer cell lines A431. Braz. Arch. Biol. Technol. 2015, 58,540-546. [CrossRef]

13. Teixeira, A.; Baenas, N.; Dominguez-Perles, R.; Barros, A.; Rosa, E.; Moreno, D.A.; Garcia-Viguera, C. Natural bioactive compounds from winery by-products as health promoters: A review. Int. J. Mol. Sci. 2014, 15, 15638-15678. [CrossRef] [PubMed]

14. Xu, Y.; Burton, S.; Kim, C.; Sismour, E. Phenolic compounds, antioxidant, and antibacterial properties of pomace extracts from four virginia-grown grape varieties. Food Sci. Nutr. 2016, 4, 125-133. [CrossRef] [PubMed]

15. Zhu, F.; Du, B.; Zheng, L.; Li, J. Advance on the bioactivity and potential applications of dietary fibre from grape pomace. Food Chem. 2015, 186, 207-212. [CrossRef] [PubMed]

16. Bocco, A.; Cuvelier, M.E.; Richard, H.; Berset, C. Antioxidant activity and phenolic composition of citrus peel and seed extracts. J. Agr. Food Chem. 1998, 46, 2123-2129. [CrossRef]

17. Conidi, C.; Cassano, A.; Caiazzo, F.; Drioli, E. Separation and purification of phenolic compounds from pomegranate juice by ultrafiltration and nanofiltration membranes. J. Food Eng. 2017, 195, 1-13. [CrossRef]

18. Brezoiu, A.M.; Matei, C.; Deaconu, M.; Stanciuc, A.M.; Trifan, A.; Gaspar-Pintiliescu, A.; Berger, D. Polyphenols extract from grape pomace. Characterization and valorisation through encapsulation into mesoporous silica-type matrices. Food Chem. Toxicol. 2019, 133, 110787. [CrossRef]

19. Drevelegka, I.; Goula, A.M. Recovery of grape pomace phenolic compounds through optimized extraction and adsorption processes. Chem. Eng. Process. 2020, 149, 107845. [CrossRef]

20. Pedras, B.M.; Regalin, G.; Sá-Nogueira, I.; Simões, P.; Paiva, A.; Barreiros, S. Fractionation of red wine grape pomace by subcritical water extraction/hydrolysis. J. Supercrit. Fluids 2020, 160, 104793. [CrossRef]

21. Krishnaswamy, K.; Orsat, V.; Gariépy, Y.; Thangavel, K. Optimization of Microwave-Assisted Extraction of Phenolic Antioxidants from Grape Seeds (Vitis vinifera). Food Bioprocess Technol. 2013, 6, 441-455. [CrossRef]

22. Caldas, T.W.; Mazza, K.E.L.; Teles, A.S.C.; Mattos, G.N.; Brigida, A.I.S.; Conte, C.A.; Borguini, R.G.; Godoy, R.L.O.; Cabral, L.M.C.; Tonon, R.V. Phenolic compounds recovery from grape skin using conventional and non-conventional extraction methods. Ind. Crop. Prod. 2018, 111, 86-91. [CrossRef]

23. Yammine, S.; Delsart, C.; Vitrac, X.; Peuchot, M.M.; Ghidossi, R. Characterisation of polyphenols and antioxidant potential of red and white pomace by-product extracts using subcritical water extraction. Oeno One 2020, 54, 263-278.

24. Ratnasooriya, C.; Rupasinghe, H.P.V. Extraction of phenolic compounds from grapes and their pomace using beta-cyclodextrin. Food Chem. 2012, 134, 625-631. [CrossRef] [PubMed]

25. Meini, M.R.; Ricardi, L.L.; Romanini, D. Novel routes for valorisation of grape pomace through the production of bioactives by Aspergillus niger. Waste Biomass Valorization 2020, 11, 6047-6055. [CrossRef]

26. Cassano, A.; Conidi, C.; Giorno, L.; Drioli, E. Fractionation of olive mill wastewaters by membrane separation techniques. J. Hazard. Mater. 2013, 248-249, 185-193. [CrossRef]

27. Cassano, A.; Cabri, W.; Mombelli, G.; Peterlongo, F.; Giorno, L. Recovery of bioactive compounds from artichoke brines by nanofiltration. Food Bioprod. Process. 2016, 98, 257-265. [CrossRef]

28. Conidi, C.; Cassano, A.; Drioli, E. A membrane-based study for the recovery of polyphenols from bergamot juice. J. Membr. Sci. 2011, 375, 182-190. [CrossRef]

29. Giacobbo, A.; Meneguzzi, A.; Bernardes, A.M.; de Pinho, M.N. Pressure-driven membrane processes for the recovery of antioxidant compounds from winery effluents. J. Clean. Prod. 2017, 155, 172-178. [CrossRef]

30. Yammine, S.; Rabagliato, R.; Vitracz, X.; Peuchot, M.M.; Ghidossi, R. Selecting ultrafiltration membranes for fractionation of high added value compounds from grape pomace extracts. Oeno One 2019, 53, 487-497. [CrossRef]

31. Palma, M.; Piiñeiro, Z.; Rostagno, M.; Barroso, C. Ultrasound-assisted extraction of compounds from foods. Ultrason. Sonochem. 2006, 4, 1-6.

32. Kunst, B.; Sourirajan, S. An approach to the development of cellulose acetate ultrafiltration membranes. J. Appl. Polym. Sci. 1974, 18, 3423-3434. [CrossRef]

33. Kong, F.X.; Sun, G.D.; Chen, J.F.; Han, J.D.; Guo, C.M.; Zhang, T.; Lin, X.F.; Xie, Y.F.F. Desalination and fouling of NF/low pressure RO membrane for shale gas fracturing flowback water treatment. Sep. Purif. Technol. 2018, 195, 216-223. [CrossRef] 
34. Afonso, M.D.; De Pinho, M.N. Ultrafiltration of bleach effluents in cellulose production. Desalination 1990, 79, 115-124. [CrossRef]

35. Ribéreau-Gayon, J.; Peynaud, E.; Supraud, S. Sciences et Techniques du Vin: Analyse et Contrôle des Vins, 2nd ed.; Bordas Editions: Paris, France, 1976; p. 645.

36. Wang, Y.; Singh, A.P.; Hurst, W.J.; Glinski, J.A.; Koo, H.; Vorsa, N. Influence of degree-of-polymerization and linkage on the quantification of proanthocyanidins using 4-Dimethylaminocinnamaldehyde (DMAC) assay. J. Agr. Food Chem. 2016, 64, 2190-2199. [CrossRef]

37. Re, R.; Pellegrini, N.; Proteggente, A.; Pannala, A.; Yang, M.; Rice-Evans, C. Antioxidant activity applying an improved ABTS radical cation decolorization assay. Free Radic. Biol. Med. 1999, 26, 1231-1237. [CrossRef]

38. Brand-Williams, W.; Cuvelier, M.E.; Berset, C.L.W.T. Use of a free radical method to evaluate antioxidant activity. LWT Food Sci. Technol. 1995, 28, 25-30. [CrossRef]

39. Nayak, A.; Bhushan, B.; Rosales, A.; Turienzo, L.R.; Cortina, J.L. Valorisation potential of Cabernet grape pomace for the recovery of polyphenols: Process intensification, optimisation and study of kinetics. Food Bioprod. Process. 2018, 109, 74-85. [CrossRef]

40. Monagas, M.; Gomez-Cordoves, C.; Bartolome, B. Monomeric, oligomeric, and polymeric flavan-3-ol composition of wines and grapes from Vitis vinifera L. Cv. Graciano, Tempranillo, and Cabernet Sauvignon. J. Agr. Food Chem. 2003, 51, 6475-6481. [CrossRef]

41. de la Cerda-Carrasco, A.; López-Solís, R.; Nuñez-Kalasic, H.; Peña-Neira, Á.; Obreque-Slier, E. Phenolic composition and antioxidant capacity of pomaces from four grape varieties (Vitis vinifera L.). J. Sci. Food Agric. 2015, 95, 1521-1527. [CrossRef]

42. Zhu, M.T.; Huang, Y.S.; Wang, Y.L.; Shi, T.; Zhang, L.L.; Chen, Y.; Xie, M.Y. Comparison of (poly)phenolic compounds and antioxidant properties of pomace extracts from kiwi and grape juice. Food Chem. 2019, 271, 425-432. [CrossRef]

43. Díaz-Reinoso, B.; Moure, A.; Domínguez, H.; Parajó, J.C. Ultra- and nanofiltration of aqueous extracts from distilled fermented grape pomace. J. Food Engin. 2009, 91, 587-593. [CrossRef]

44. Nilsson, J.L. Protein fouling of UF membranes: Causes and consequences. J. Membr. Sci. 1990, 52, 121-142. [CrossRef]

45. Arsuaga, J.M.; López-Muñoz, M.J.; Sotto, A. Correlation between retention and adsorption of phenolic compounds in nanofiltration membranes. Desalination 2010, 250, 829-832. [CrossRef]

46. Jönsson, C.; Jönsson, A.S. Influence of the membrane material on the adsorptive fouling of ultrafiltration membranes. J. Membr. Sci. 1995, 108, 79-87. [CrossRef]

47. Sotto, A.; Arsuaga, J.M.; Van der Bruggen, B. Sorption of phenolic compounds on NF/RO membrane surfaces: Influence on membrane performance. Desalination 2013, 309, 64-73. [CrossRef]

48. Moreno, J.; Peinaldo, R. Grape Acids. In Enological Chemistry, 1st ed.; Academic Press-Elsevier: Amsterdam, The Netherlands, 2012; pp. 121-135.

49. Giacobbo, A.; Bernardes, A.M.; Filipe Rosa, M.J.; de Pinho, M.N. Concentration polarization in ultrafiltration/nanofiltration for the recovery of polyphenols from winery wastewaters. Membranes 2018, 8 , 46. [CrossRef]

50. Galanakis, C.M.; Markouli, E.; Gekas, V. Recovery and fractionation of different phenolic classes from winery sludge using ultrafiltration. Sep. Purif. Technol. 2013, 107, 245-251. [CrossRef]

51. Yammine, S.; Rabagliato, R.; Vitracz, X.; Peuchot, M.M.; Ghidossi, R. The use of nanofiltration membranes for the fractionation of polyphenols from grape pomace extracts. Oeno One 2019, 53, 11-26. [CrossRef]

Publisher's Note: MDPI stays neutral with regard to jurisdictional claims in published maps and institutional affiliations.

(C) 2020 by the authors. Licensee MDPI, Basel, Switzerland. This article is an open access article distributed under the terms and conditions of the Creative Commons Attribution (CC BY) license (http://creativecommons.org/licenses/by/4.0/). 